\title{
FÚTBOL: DEPORTE Y CIVILIZACIÓN
}

\author{
Eduardo Arroyo Laguna \\ Universidad Ricardo Palma
}

El actual campeonato mundial de fútbol revela la conversión de este deporte en una pasión global. El panorama es el de disfrute multitudinario paralizando las ciudades y todo el planeta. El goce como la frustración son colectivos. El fútbol ha ingresado a la civilización del espectáculo como del consumo. Ha incorporado el colorido de los desfiles, circo y concierto, bandas, fuegos artificiales y la parafernalia de la exposición publicitaria moderna.

\section{ESPECTÁCULO Y NEGOCIO}

Es un gran show. El sistema lo convierte todo en oferta visual con sus cheer leaders (waripoleras), barristas, colores, lemas, movimientos. Hay mucha inversión monetaria de parte de las grandes marcas auspiciadoras del balompié, las que son sacralizadas como modernos fetiches expresando el turboconsumismo (Lipovetsky, 2007, pp. 96-104) que compra lo que no necesita porque es adicto al mercado y a gastar en el último grito de la moda. Indica el paso de la edad de la elección a la edad de la hiperelección, del monoequipamiento al multiequipamiento, del consumismo discontinuo al consumismo continuo, del consumo individualista al hiperindividualista, aquel que crea de manera autónoma su propio espacio-tiempo gracias a las compras en línea (redes electrónicas) con la compulsión de ganar tiempo. Lo quiere todo y enseguida.

El mercado manda y ha convertido al fútbol en el más bello espectáculo universal y negocio indudable. El planeta vibra con cerveza Budweisser.

Es presentismo amplio. En el presente pareciera que muchos se juegan la vida y se lo vive hasta las últimas consecuencias. Presentismo, individualismo, imagen y consumo. No hay un negocio más rentable que globalice a todo el planeta. El fútbol es consagrado en los altares, fetichizado aunque al final sea mera fantasía porque al margen de cuan hermoso sea 
el jogo bonito sigue la crisis climática, financiera como la recesiva. Nada cambia en la realidad pero el mundo necesita de estos grandes espacios de desahogo y evasión simbólica.

Los centros comerciales son las catedrales modernas del consumo mientras los estadios concentran la fe deportiva. Es el colectivismo de nuestros tiempos.

\section{EL FIN DE LAS IDEOLOGÍAS Y LAS NUEVAS PASIONES}

Vivimos en una época marcada por el fin de las ideologías y las utopías y por tanto el descreimiento, el nihilismo, el presentismo, el realismo, consumismo, el individualismo, la vida simple y pragmática cuando no un sentido fatalista de la misma y mil vacíos que se llenan con puro consumo. Consumo para la alegría, consumo para la depresión. El sistema tiene todo tipo de oferta para todo tipo de demanda. Te vacía de contenido y tú consumes para llenar esos vacíos que te crea el propio sistema.

Todo es mercado, todo es consumo. Homo consumericus, diría Lipovetsky; homo videns, ganado por las imágenes, pontifica Sartori ante el descreimiento en los viejos sentidos de la vida.

Por otro lado, sin embargo, emergen creencias masivas, intolerancia $\mathrm{y}$ fundamentalista guerra santa como nuevas mentalidades colectivas.

Tal vez sea que en un mundo sin horizontes utópicos, como predica el mercado desde el Consenso de Washington (1990), hegemonizado por el mercado neoliberal, abierto a la inversión extranjera sin cortapisas, parecieran haberse fortalecido civilizaciones y culturas vernáculas, naciones, religiones. No se ha podido lograr el borrado de fronteras y abrir las aduanas al ingreso libre de capitales sin reglas, si bien vivimos bajo el dominio de un pensamiento único de mercado (Forrester, 2012).

Al final del campeonato mundial de fútbol, nos preguntamos quién ganó con la millonaria inversión en estadios y construcciones en un país que precisamente se caracteriza por la baja inversión en infraestructura, bajo cubrimiento de servicios de salud, educación, vivienda y trabajo, todo aquello básico para asegurar reales niveles de desarrollo. No es Brasil el país que más crece en Latinoamérica y en el mundo, el de mayor producción y empleo. Tras el adormecimiento creado por la tregua mundialista, las movilizacio- 
nes sociales en busca de mejores servicios de transporte, salud y educación, volverán a las calles y plazas. Más aún, cuando la inversión millonaria en infraestructura deportiva en todo el país, no ha permitido al pentacampeón alzarse con la Copa sino ser reducido a un modesto cuarto lugar, tras varias hecatombes deportivas propias de haber vivido bajo la concepción medieval redentorista y mesiánica de que los países y equipos dependen de un solo jugador. El futuro del PT y de Dilma Rousseff penden de un hilo.

Estos medievalismos, gran enseñanza de este campeonato, nos han hecho ver que la modernidad va aparejada a la idea de progreso, de cambio social, de eficacia, de eficiencia, de planeamiento estratégico, de gol, de verdaderas maquinarias y equipos afiatados, no decaudillos que al desaparecer dejan al equipo y al país sin liderazgo.

\section{NEOTRIBUS Y MODERNA RELIGIÓN DE MASAS}

Nuestra época es hija de la cultura de la globalización y de la cultura de la imagen como del hedonismo moderno necesitado de creer pero con placer, no con austeridad, con relajo no con estoicismo, mundo más epicúreo que apolíneo, más dionisiaco, bohemio o báquico que controlado, más extravertido que introvertido o reflexivo como enseñan los artistas de la televisión. Es el culto a la emoción desnuda sin apelar nunca al control y la reflexión.

Ya no aparecen religiones platónicas sino placenteras, ofreciendo un paraíso orgiástico a la vuelta de la esquina.

Las masas movilizadas por el contagio afectivo generan personalidades diametralmente opuestas a las solitarias. Protagoniza la escena mundial la multitud, la comunidad emocional, aquella que no puede ser codificada, una potencia protoplasmática que invade todos los órdenes de lo social (Maffesoli, 1990, p. 10).

El fútbol no es un deporte de élites, sin dejar de decir que los haya y que pueda agradar a pequeñas castas de poder intelectual o económico, destacándose porque congrega a vastos sectores de la humanidad.

Pero ante el descreimiento generalizado, el no creer en nada (nihilismo), el fútbol cumple un papel catalizador. Llena vacíos existenciales por un fenómeno de desplazamiento emocional. Se ha convertido en una suerte de religión secular, masiva, laica, seglar. Como si una religión llenara el vacío que te deja otra. Por eso al lado del descreimiento propio 
de la posmodernidad, se da el fanatismo de grandes masas alentando a sus equipos bajo sus banderas, colores e himnos patrios.

Asombrosamente si la muerte de ideologías se da en el mundo occidental y cristiano, en otras latitudes se han fortalecido más bien las civilizaciones, naciones y religiones. Es que, como dice Norbert Elías, el concepto de civilización expresa la autoconciencia de Occidente, todo aquello que la sociedad occidental de los últimos dos o tres siglos cree llevar de ventaja a las sociedades anteriores o a las contemporáneas "más primitivas" reflejando así su peculiaridad y aquello de lo que se siente orgullosa, sea por sus técnicas, concepción del mundo y mil cosas más (Norbert, p. 83). La muerte de las ideologías y utopías es básicamente occidental.

De un lado se da el consumismo y el individualismo; del otro, movidos por lo que Maffesoli llama "contagio afectivo", los individuos se esconden en las masas organizando neotribus que ganan las calles, nómades, en busca de la emoción y la aventura, de afecto, de aprecio, de reconocimiento (aquello que Hegel sostiene es el motor de la historia humana), de una fé por qué vivir, una ilusión.

El individualismo exacerbado por el sistema neoliberal fomenta el culto del yo personal fomentándose el narcisismo, la egolatría, el culto a la individualidad. Hemos recuperado nuestro yo y lo hemos llevado al Olimpo del templo de lo individual. Yo soy mi Dios. Dios ha muerto, yo soy el nuevo Dios. Pero asombrosamente como diría Maffesoli, el contagio afectivo lleva a que se recupere el yo colectivo, el nosotros y el individuo idolatrado se fusiona con las masas, se hace una masa, se hace uno con el nosotros. Si bien el neoliberalismo libera al individuo al máximo, en las tribus se fusionan los yoes detrás de una personalidad superior. Tribus salvajes, callejeras invaden los espacios y nosotros que hemos perdido las plazas, otrora espacios de expansión diaria, recuperamos gracias al futbol los espacios públicos, que ya no necesariamente son las plazas y calles, sino los estadios, bares, cantinas, mercados, centros comerciales, verdaderas plazas del ser humano contemporáneo, centros comerciales, nuevos templos de la civilidad actual.

El individuo se pierde en la masa global y adquiere identidad colectiva, propia de su carácter orgiástico que es siempre colectivo, tribal, perdiéndose las fronteras entre sus componentes. Goce del presentismo ante la imposibilidad de ver horizontes o la grisura de una vida sin utopías. El individuo que el globalismo recupera con el individualismo y que es su aspecto aceptable termina perdiéndose en la masa global la que adquiere 
identidad colectiva, tribal, en donde el futbol como religión moderna subsume los yoes y los hace una sola masa.

El contagio afectivo indica la gran necesidad de afecto popular y masivo que tienen los pueblos y que ante la caída de las ideologías y utopías, sin dejar sus religiones respectivas, encuentran en el futbol una vía para canalizar sus esperanzas, sus destinos como nación, como colectividades nacionales.

El contagio afectivo que transmite el futbol subsume los yoes y los hace una sola masa social. El contagio afectivo (ver al papa Bergoglio, Francisco I luciendo su casaquilla del Rosario Fútbol Club, ya es bastante significativo) lleva a la hinchada, al admirador, al adicto, el que te sigue no importa que no campeones, pero te tienen cariño y siempre estará contigo en las buenas y en las malas.

Este deporte une, apasiona, fusiona colectividades. Tiene mucho de religión por cuanto hay fe en los jugadores, en los equipos, hay esperanza, hay gozo. Como en toda religión hay jerarquías. El Estado Mayor, la FIFA sería una suerte de Vaticano, los popes del deporte, los equipos son la feligresía y el pueblo de dios con códigos, marcas, etc. Los talibanes de las barras bravas son los guerreros del siglo XXI capaces de matar por quítame estas pajas. Talibanes estandarizadores, homogenizadores. Abajo la tolerancia a la que llama Naciones Unidas, viva la intolerancia, viva mi equipo. Patria o muerte. La estandarización se logra por la fuerza si bien se matiza con la belleza de los colores, de sus mujeres, de su alegría, de sus himnos, sus hinchas, sus canciones, sus barras, sus botas de vino, etc. Es una fe que desplaza multitudes de sus países de origen a los estados en los que los equipos luchan por llegar a finales, al triunfo, al gol, al éxito.

Es una religión moderna, secular, laica de masas. Tiene un carácter ecuménico, no sectario por cuanto fusiona a equipos musulmanes, budistas, católicos, protestantes. Es más ecuménica que cualquier religión congregando a todos sin cortapisas de raza, religión, credo, edad, clase social o grado de instrucción. Une a pueblos aunque también genera guerras.

En estos días en que se han matado las ideologías y las utopías achatando miserablemente la existencia y fomentando el descreimiento, el pragmatismo y la abulia existencial como el nihilismo, solo queda a un grueso sector de la humanidad vivir con el ojo puesto en la televisión, aclamar el gol, la jugada genial, el pase colosal, la atajada del arquero ante un penal siempre difícil. 
Cunde el desborde, el descontrol, el carnaval. La humanidad entera sigue día a día cada uno de sus encuentros y comenta, se come las uñas sin importar las diferencias de género, de edades, raza, credo o clase social. Fusiona a todos por igual. El trabajo se paraliza y las calles quedan desérticas. Como cuando canta Roberto Carlos "Todo para cuando hacemos el amor". Gozo y sufrimiento, expectativa y desesperanza, fe y descrédito, caras de la misma moneda, signos de una nueva religión moderna.

Casi diría que en estos veinte y cinco años en que el sistema nos ha repetido hasta la saciedad que han muerto las ideologías y las utopías, si bien se nos ha sobrecargado con la presión ideológica del mercado (de la imagen, del consumo, del yo) y de este modo se ha querido achatar la existencia, el fútbol se ha convertido en la moderna religión masiva de los países, de la humanidad entera. Las naciones y sus equipos son las iglesias modernas con grandes feligresías ilusionadas por sus casaquillas tratándole de arrancarle un gol a la vida, siempre esquiva en los triunfos y logros. e histeria.

Mucho símbolo se concentra en el fútbol. Fútbol y pasión. Futbol

Es también en esta era de identidades globales un rebrote del nacionalismo, del militantismo en el amor y afecto por las naciones. Surgen nuevas potencias futbolísticas como Costa Rica, Irán, Argelia; numerosos equipos latinoamericanos ingresaron a octavos de final. Todo está en cambio. En Afganistán hay mucho fútbol popular como en Marruecos, Irán y Pakistán. Costa Rica es la gran revelación epocal y el mundo celebra su aparición.

Por psicología de masas sabemos que todos queremos ser incluidos. Por ello, todos ven el futbol. Hay también mucho de superficialidad y de espíritu de manada.

A estas feligresías ilusionadas por sus casaquillas se añade la eclosión de grupos religiosos que se hacen masivos y se extienden en el Perú, caso de los evangélicos y diversos grupos protestantes como los del Pacto Israelita, los Hare Krishna, los Mahikari y muchos otros. En un rush impresionante ganan adeptos en estos tiempos de cólera ofreciendo la salvación a tanto desarrapado, a tanta persona necesitada de comida y afecto.

\section{EL SIGNIFICADO DEL GOL}

Los corazones se exaltan con el esfuerzo de los jugadores. En cada partido no solo se juega el esfuerzo y el triunfo o derrotas deportivas sino 
que cada oyente, televidente o espectador se juega un partido aparte, el partido de su vida personal, de sus ansias, sus expectativas, sus sueños. Los goles llenan los espíritus y los equipos comulgan con los espectadores. Cuerpo místico, comunión total.

El esfuerzo de los jugadores crea identidades y cada gol es el éxito, el triunfo, la culminación del esfuerzo desplegado.

Cómo imaginar que 22 jugadores corriendo detrás de una pelota tras el ansiado gol en la valla enemiga puedan generar esta pasión, electrocutar a la humanidad entera, es un asunto no fácil de explicar.

El éxito planteado por el sistema vigente es el triunfo en base a la escala de valores del sistema, la que te da estima social y una alta autoestima. El sistema te plantea retos, problemas y tabla de logros y el gol es la meca, el cumplimiento de tus objetivos, de tu planeamiento estratégico. Denota eficacia, eficiencia y calidad total.

El contagio afectivo del fútbol enlaza a la humanidad que celebra goles ajenos como propios, como símbolos del triunfo frente a tanta derrota en la vida cotidiana.

Un equipo nacional se impone sobre otro. El gol representa el poder sobre el otro, mide un país ante otro, una persona ante otra. El goleador se pasea ufano ante la tribuna, es el héroe por unos segundos, pasa a la historia, es inmortal. Cada jugador juega su inmortalidad. Exhibe su poder con gestos propios que engrandecen su hazaña y los exhibe abiertamente ante el público. Exhibe su afán de poder, su poderío. Es opio, es símbolo, es también evasión pero es triunfo aunque sea episódico y el individuo se pierde en la masa para celebrar. Es el gol arrancado al gris de la vida. Por ello se celebra como si en él se fuera toda la vida. Es también superficialismo en donde se pierden muchas identidades febles, lábiles, frívolas, poco profundas, aunque todos se apasionen por el fútbol, seres profundos y superficiales.

El gol es el símbolo del logro arrancado a la adversidad, a las dificultades del sistema opresor lleno de trámites, de regulaciones, de taxativas, de impuestos. Es el gol arrancado a la vida identificándote con el equipo de tus amores o adoptando un equipo.

Ello hace del fútbol un deporte masivo, tal vez porque sea pedestre como opinan algunos porque es un juego con los pies aunque también 
implica un buen manejo del conjunto del cuerpo, elasticidad motora, manejo de todos los hemisferios cerebrales, jugar con el conjunto del equipo, tomar decisiones todo el tiempo y combinar la adrenalina con la inteligencia, el tino, el tacto del pase, del apoyo a los compañeros de la cancha.

Termina así siendo el deporte más popular, más idolatrado, congregador de multitudes que en cada partido se juega sus ilusiones desbocadas detrás de un equipo, unas piernas, unos chimpunes, una pelota, un gol, un triunfo. Por ello el futbol es masivo y planetario. El rugby prima en EE. UU. así como el basketball; el base ball en EE. UU. y Centro américa, por lo que es sorprendente el desempeño de Costa Rica en este campeonato.

Es el deporte más completo y complejo que capta y apresa la identidad y simpatía de los pueblos.

\section{CRECIMIENTO ECONÓMICO Y CAMPEONES}

No hay una relación directa entre la infraestructura y la superestructura, entre el crecimiento y los triunfos deportivos.

Sin embargo, al intentar correlacionar el crecimiento económico con sus expresiones futbolísticas, salen unas primeras conclusiones. Una España quebrada y que ostentaba nada menos que el título de campeón mundial, fue abatida rápidamente en dos jornadas. Alemania, el país más sólido de la Unión Europea, es una verdadera máquina de jugar fútbol y esa unidad de equipo lo ha llevado a lograr el campeonato mundial. Es un fútbol moderno el que practica, señal de modernidad mientras otros equipos juegan con la mentalidad feudal del mesías salvador, caso de los brasileños y tal vez los argentinos. Este mundial ha expresado a la modernidad (Alemania, Holanda) frente a las tradiciones (nuestras raíces) y los tradicionalismos (que llevan a vivir anclados en el pasado).

Cerca de nueve equipos latinoamericanos llegaron a octavos de final. Los asiáticos pese a su carácter avasallador como tigres y dragones de Asia fueron eliminados rápidamente al igual que los africanos, que tienden a quedarse en el cuarto mundo.

Es también un mentís para el Perú cuyas autoridades deportivas creen que con cuatro estrellas lograremos la ansiada clasificación. Nada de eso. 
La modernidad es entrenamiento, plan estratégico, eficacia, eficiencia y por más buenos que sean los jugadores peruanos individualmente en sus equipos extranjeros, hay que constituir una maquinaria, una unidad, un equipo lo que requiere de un corazón diferente necesitado de la palabra patria, del amor al ancestro, a la tierra, no del cuidado de las piernas jugando del mejor modo en el extranjero pero nunca así en el Perú y por el Perú.

Falta patriotismo indudablemente, aquello que esta globalización ha intentado anular y que en el caso del Perú ha llevado a las que generaciones jóvenes no conozcan de la historia patria ni del amor a la patria.

Brasil con un crecimiento reducido ofrece un futbol poco contundente si lo consideramos con otras décadas, muy ilusionados con una estrella que lesionado en un acto aleve, desapareció dejando al equipo abandonado a su suerte, el que perdió estrepitosamente ante los alemanes y holandeses.

\section{BÚSQUEDA DE HÉROES, DE MODELOS}

Ante el gris de la vida, la humanidad busca héroes, modelos a seguir. No los encuentra en los políticos ni en los financistas de la banca internacional, los que expresan más bien a la parca del hambre, la muerte, la corrupción, la escasa transparencia, el afán de poder, la búsqueda del poder por apetitos personales, la falta de sensibilidad.

Por ello, las masas buscan muchas veces en el pasado a sus modelos a seguir. Revive una historia contada por Tolkien en el año 1954 bajo el nombre de "El señor de los anillos" que nos trae a los héroes Aragorn, los hobbits, Arwen como "Corazón valiente" de que se nutre Hollywood ya que el mercado no tiene en quien inspirarse; Gladiador, Corazón de caballero, Troya, Alejandro Magno, Julio César, La guerra de las galaxias, Harry Potter o en el futbol encuentra a sus ídolos en James Rodríguez, Neymar, Messi, Cristiano Ronaldo, Robben. Este ha sido un mundial de grandes arqueros y hay infinidad de modelos a imitar, todos de alto profesionalismo.

Nuestros adolescentes y jóvenes necesitados de modelos exitosos en la línea que la globalización fomenta, los busca para intentar aunque sea arañar el cielo. Todos necesitan de un modelo triunfador a seguir por lo que la gente se identifica con sus cracks y se proyecta en ellos.

El triunfo es la reafirmación del yo en el nosotros colectivo. Los triunfos afianzan la seguridad de las naciones, de sus miembros constitu- 
tivos, de sus ciudadanos. No se puede vivir eternamente de derrotas. Ese carácter nacional y religioso del deporte expresa el feeling de los pueblos, de su mundo de emociones y sentimientos. El fútbol se convierte en un sentimiento, una pasión, como el amor, como esos boleros que todos tenemos clavados en el fondo del alma.

Las estrellas James Rodríguez, Messi, Neymar, el arquero Julio César, Ochoa el arquero mexicano, Bravo el arquero chileno, Romero el argentino, Neuer el alemán, Navas el costarricense, son los nuevos héroes en este mundial de definición por penales, mundial de arqueros.

En fin, divertimento, creencia masiva, fiesta, orgía, fiesta y siesta en que ha andado el planeta por más de un mes olvidando que mientras se jugaba, Israel destruía la Franja de Gaza con más de dos mil muertos palestinos y los conflictos en Siria y Ucrania siguen por la acción del imperio del norte como de las potencias por adquirir los energéticos que permitan mantener sus hegemonías en el mundo.

En el virtuosismo del futbol hecho espectáculo se va mucho de la vida, la creatividad, el ingenio popular, la picardía, la ensoñación, el quitarle una derrota a la vida con un gol o la gracia de una buena jugada.

\section{REFERENCIAS BIBLIOGRÁFICAS}

FORRESTER, Viviane

2002 Una extraña dictadura., México: Fondo de Cultura Económica

LIPOVETSKY, Gilles

2007 La felicidad paradójica. Ensayo sobre la sociedad de hiperconsumo. Barcelona: Editorial Anagrama,

MAFFESOLI Michel

1990 El tiempo de las tribus. El declive del individualismo en las sociedades de masas. Prólogo de Jesús Ibáñez. ICARIA.

NORBERT, Elías

El proceso de la civilización. Investigaciones sociogenéticas y psicogenéticas. $2^{\mathrm{a}}$. reimpresión. México: Fondo de Cultura Económica, 